\title{
PREVALENCE OF METABOLIC SYNDROME IN WOMEN WITH POLYCYSTIC OVARIAN DISEASES IN A OUTDOOR SETTING
}

\author{
Shahanara Chowdhury ${ }^{1}$ Afroza Ferdous ${ }^{2}$
}

\begin{abstract}
Summary
Polycystic ovarian diseases (PCOD) is a condition associated with chronic anovulation, insulin resistance and androgen access. Women with this syndrome are at increased risk of metabolic syndrome. The aim of the present study was to determine the prevalence of metabolic syndrome (MBS) in women with PCOD in a private outdoor setting in different ages and body mass index (BMI). A cross sectional study was conducted in a private clinic setting. A total of 146 women with PCOD ages between 15-40 years included. The prevalence of metabolic syndrome and its components in these population were the outcomes. Height, weight, waist circumference, blood pressure and the laboratory tests (FBS,TSH,HDL$C$, serum prolactin, triglycerides and total cholesterol) were measured in this population. The prevalence of MBS in PCOD women was $24 \%$ (36 cases). The rate of central obesity, $F B S$ more than $110 \mathrm{mg} / \mathrm{dl}$, triglycerides more than $150 \mathrm{mg} / \mathrm{dl}$, highdensity lipoprotein cholesterol levels (HDL-C) less than $50 \mathrm{mg} / \mathrm{dl}$, and blood pressure 130/85 $\mathrm{mmHg}$ in PCOD women was $29.45 \%$ (43), $4.10 \%$ (6), $34.93 \%$ (51), 66.43\% (97), and $10.27 \%$ (15), respectively. The risk of MBS was increased in older and the obese women (BMI $\left.30 \mathrm{~kg} / \mathrm{m}^{2}\right)$. The present study shoewd that women with PCOD have high prevelance of MBS \& its individual components, particularly decressed $\mathrm{HDL}-\mathrm{C}$.
\end{abstract}

Key words

Prevalence; polycystic ovarian diseases; metabolic syndrome

\section{Introduction}

Polycystic ovarian Diseases(PCOD) is a condition associated with chronic anovulation, insulin resistance and androgen excess. It is considered to be one of the most common endocrinopathies among reproductive age women. It affects approximately 6$10 \%$ of reproductive-age women [1].

1. Professor of Obstetrics \& Gynecology Chittagong Medical College, Chittagong

2. Assistant Professor of Obstetrics \& Gynecology Chittagong Medical College, Chittagong

Correspondence : Dr Shahanara Chowdhury
Some clinical manifestations of PCOD are hyperandrogenism, oligomenorrhea or amenorrhea, hirsutism and chronic anovulation. Women with this diseases are at increased risk of metabolic syndrome (MBS). MBS consists of a constellation of metabolic abnormalities that confer increased risk of cardiovascular disease and diabetes mellitus [2].

"The National Cholesterol Education Program Adult Treatment Panel (NCEPATP III) guidelines define MBS as having three or more of the following abnormalities:

1. Waist circumference in females greater than $88 \mathrm{~cm}$.

2. Fasting serum glucose at least $110 \mathrm{mg} / \mathrm{dl}$.

3. Fasting serum triglycerides at least $150 \mathrm{mg} / \mathrm{dl}$.

4. Serum high density lipoprotein cholesterol (HDL-C) less than $50 \mathrm{mg} / \mathrm{dl}$.

5. Blood pressure at least $130 / 85 \mathrm{mmHg}$ [3].

Although insulin levels are not used to diagnose either PCOD or MBS, however insulin resistance and compensatory hyperinsulinemia are key pathogenic factors in the pathogenesis of these disorders [2]. It seems the prevalence of MBS in PCOD patients is higher than general population.

United States studies confirmed the prevalence of the MBS in PCOD women (43-46\%) was nearly 2-fold higher than that reported for aged-matched women in the general population [4,5]. Two different studies which were conducted in Iran had controversy.

The first study by Lankarani et al manifested the criteria for MBS are frequently present in young women with PCOD and more useful as a prognostic factor than insulin resistance. Meanwhile they suggested the evaluation of insulin resistance in older age women with PCOD [6].

Another case-control study showed MBS was no frequent in a sample of PCOD in Iranian population than in healthy control [7]. It seems evaluation of MBS in PCOD patients needs more investigation. Therefore, the aim of the present study was to determine the prevalence of MBS in women with PCOD referred to private clinic in different ages and body mass index (BMI). 


\section{Materials and methods}

We evaluated 146 women with PCOD who referred to the outdoor setting of private Clinic from September 2008 to September 2011. Informed consent was obtained from all participants.

PCOD patients were diagnosed by two out of three following criteria:

(1) Irregular menstruation,

(2) Clinical and / or biochemical signs of hyperandrogenism and

(3) Polycystic ovaries (presence of 12 or more follicles in each ovary, 2-9 $\mathrm{mm}$ in diameter and/or increased ovarian volume $>10 \mathrm{~mL}$ ) [8].

Irregular menstruation was defined as oligomenorrhea (eight or fewer menstrual periods annually) or amenorrhea (abnormal suppression or absence of menstruation). MBS was diagnosed using the Adult Treatment Panel-III (ATP III) guidelines when any three of the following were present: central obesity, raised triglycerides $150 \mathrm{mg} / \mathrm{dl}$, highdensity lipoprotein (HDL) cholesterol $<50 \mathrm{mg} / \mathrm{dl}$, blood pressure $130 / 85 \mathrm{~mm} \mathrm{Hg}$ and fasting blood glucose (FBS) $110 \mathrm{mg} / \mathrm{dl}[3]$.

\section{Exclusion criteria}

PCOD women younger than 15 years old (due to the possibility overlap with other conditions associated with hyperandrogenism such as congenital adrenal hyperplasia), women older than 40 years (to avoid potential overlap with perimenopause), hyperprolactinemia and hypothyroidism (measure of serum prolactin and TSH levels).

\section{Inclusion criteria}

Age 15-40 years, no medication use which affected sex hormones from six months prior to study onset (eg, oral contraceptives and metformin). Information data and reproductive history of all cases were recorded, such as: age, age of menarche, history of pregnancy and infertility. Height, weight, waist and hip circumferences were measured by the nursing staff. Blood pressure was measured twice in either the right or left arms after the patient was seated and at rest for a minimum of $15 \mathrm{~min}$. The systolic and diastolic measurements reported represented the mean of the two readings.

Patients were stratified into the following: group 1:16-20 years, group 2: 21-25 years, group 3: 26-30 years, group 4: 31-35 years and group 5: 36-40 years; and BMI categories <18.5, 18.5-24.9, 25-29.9, and $>30$. Waist circumference greater than $88 \mathrm{~cm}$ was considered as central obesity and was measured at the level of the umbilicus with flexible tape.
Laboratory tests were performed in only one private diagnostic labortory and included: FBS, HDL-C, serum prolactin, TSH, triglycerides and total cholesterol. TSH and prolactin were measured by ELISA.

\section{Statistical analysis}

Statistical analysis was performed with SPSS software (version 13). Data were presented as mean \pm standard deviation and percentages (numbers), when appropriate. The comparison between continuous variables was performed with 'ttest'. A two-tailed $\mathrm{p}$ value of less than 0.05 was considered significant.

\section{Results}

Table I : The rate of metabolic syndrome components in total PCOD population and metabolic syndrome women.

\begin{tabular}{lll}
\hline & PCOD (n- 146) & MBS (n- 36) \\
\hline Central obesity & $29.45 \%(43)$ & $50 \%(18)$ \\
FBS $>110 \mathrm{mg} / \mathrm{dl}$ & $4.10 \%(6)$ & $13.88 \%(5)$ \\
Triglycerides $>150 \mathrm{mg} / \mathrm{dl}$ & $34.93 \%(51)$ & $72.22 \%(26)$ \\
HDL-C $<50 \mathrm{mg} / \mathrm{dl}$ & $66.43 \%(97)$ & $86.11 \%(31)$ \\
BP $>130 / 85 \mathrm{mmHg}$ & $10.27 \%(15)$ & $36.11 \%(13)$
\end{tabular}

Data are presented as a percentages with number

Prevalence of MBS in PCOD women was $24 \%$ and occurred in 36 out of 146 subjects. The rate of metabolic syndrome components in total PCOD population and women with metabolic syndrome is shown in table I.The most important component in PCOD population was HDL-C less than $50 \mathrm{mg} / \mathrm{dl}$ which was manifested in $66.43 \%$ of the present sample.

Table II : The frequency of PCOD and MBS in different categories.

\begin{tabular}{lllll}
\hline & Age & $16-20 \mathrm{yrs}$ & $21-30 \mathrm{yrs}$ & $31-40 \mathrm{yrs}$ \\
\hline$*$ & PCOD & $5(3.42)$ & $98(67.12)$ & $43(29.45)$ \\
$* *$ & MBS & $0 / 5(0)$ & $22 / 98(22.44)$ & $14 / 43(32.55)$ \\
\hline$*$ & Data are presented as numbers (percentages). \\
$* *$ & $\begin{array}{l}\text { Percentages in MBS refer to percentages } \\
\text { within age categories. }\end{array}$
\end{tabular}

Table II shows the frequency of PCOD and MBS in different age categories. It was revealed that the risk of MBS increased with age. 
Table III : The frequency of PCOD \& MBS in different BMI categories

\begin{tabular}{|c|c|c|c|c|}
\hline BMI & $<18.5$ & $18.5-24.9$ & $25-29.9$ & $>30$ \\
\hline * $\mathrm{PCOD}$ & $3(2.05)$ & $36(24.65)$ & $61(41.78)$ & $46(31.50)$ \\
\hline ** MBS & $0 / 3(0)$ & $3 / 36(8.33)$ & $13 / 61(21.31)$ & $30 / 46(65.21)$ \\
\hline
\end{tabular}

Meanwhile, the frequency of PCOD and MBS in BMI categories is shown in table III. The risk of MBS increased in the obesity category (BMI 30 $\mathrm{kg} / \mathrm{m} 2$ ), where $65.21 \%$ of PCOD patients who had BMI $30 \mathrm{~kg} / \mathrm{m} 2$ manifested MBS.

Table IV : Comperison of PCOD women with and without metabolic syndrom

\begin{tabular}{|llcl|}
\hline Variables & $\begin{array}{l}\text { Without } \\
\text { MBS, } \mathrm{n}=110\end{array}$ & $\begin{array}{c}\text { With MBS } \\
\mathrm{n}=36\end{array}$ & p-value \\
\hline Age & $26.48 \pm 4.15$ & $30.05 \pm 4.01$ & $<0.0001$ \\
BMI & $26.47 \pm 4.22$ & $31.03 \pm 4.23$ & $<0.0001$ \\
\hline
\end{tabular}

Data are means \pm standard deviation

As shown in table IV, women with MBS were significantly older than others $(\mathrm{p}<0.0001)$.

\section{Discussion}

The results of our study show the frequency of MBS in reproductive age women with PCOD to be $24 \%$ which is similar to the prevalence of MBS in other ethnicities and races diagnosed with PCOD $[9,10]$. However in some ethnic groups, such as the American population, the prevalence is higher than our study, at about $40 \%[4,5]$. These differences are possibly related to factors such as age, diet and lifestyle that cause increased waist circumferences, hypertriglyceridemia and reduced HDL cholesterol levels as important components for MBS.

Azizi et al study which was performed in an urban population of Tehran has shown the prevalence of MBS in women was more commonly seen than in men and it was estimated to be $26.1 \%$ at ages $20-39$ years old [11].

The results of a case-control study in Iranian population manifested, the criteria of MBS was frequently higher in young women with PCOD [6] It may be due to different diagnosis criteria for MBS and sample size.

In the present study the rate of MBS increased by age with a markedly higher prevalence than the $6.7 \%$ MBS prevalence reported in women between the ages of 20-30 years and the $15 \%$ prevalence reported in women ages 30 40 years from the Third National Health and Nutrition Examination Survey (NHANES III) [12].
The pathogenesis of MBS and its components are complex and not well understood, although insulin resistance and perhaps hyperinsulinemia are considered to be key pathogenic factors in the development of other components of MBS such as abnormal glucose tolerance, dyslipidemia and hypertension [2].

Based on the results of the present study, the high rate of HDL-C $<50 \mathrm{mg} / \mathrm{dl}$ ( $86.11 \%$ of cases) with MBS, and triglycerides $150 \mathrm{mg} / \mathrm{dl}(72.22 \%$ of cases) manifested a significant abnormal lipid profile in PCOD women. Many studies have shown low HDL-C levels, which is one component of the lipid profile that indicates which MBS has an important role in the increasing risk of cardiovascular and coronary artery disease [13-15]. Therefore it is appropriate to be concerned when HDL-C levels are less than $50 \mathrm{mg} / \mathrm{dl}$, particularly in high risk populations. Two important factors in the increasing rate of MBS are age and BMI. By categorization of patients by age and BMI, we found increased MBS with age and BMI (Tables I, II).

Thus as described above, we propose that the criteria of MBS especially HDL-C in all patients with PCOD must be evaluated, particularly in elder and obese patients. It must be mentioned that since the samples were collected from only one private diagnostic lab so the resulted prevalence may not be generalized and further study with more samples is required. In conclusion, the present study indicates that women with PCOD have a high prevalence of MBS and its individual components, particularly decreased HDL cholesterol levels. Therefore the management of these women as a high risk population for MBS is recommended.

\section{Disclosure}

All the authors declared no competing interestes.

\section{References}

1. Knochenhauer ES, Key TJ, Kahsar-Miller M, Waggoner W, Boots LR, Azziz R. Prevalence of polycystic ovary syndrome in unselected black and white women of the southeastern United States: a prospective study. J clin Endocrinol Metab 1988; 83: 3078-3082.

2. Fauci AS, Braunwald E, Kasper DL ,Hauser SL, Longo DL, Jameson JL et al. Harrison's principles of internal medicine; 2008; 17:1509-1513.

3. Third Report of the National Cholesterol Education Program (NCEP). Expert panel on detection, evaluation, and treatment of high blood cholesterol in adults (Adult Treatment Panel III) final report. Circulation 2002; 106: 3143-3421. 
4. Glueck CJ, Papanna R, Wang P, Goldenberg N, SieveSmith L. Incidence and treatment of metabolic syndrome in newly referred women with confirmed polycystic ovarian syndrome. Metabolism 2003; 52: 908-915.

5. Apridonize T, Essah PA, Iuorno MJ, Nestler JE. Prevalence and characteristics of the metabolic syndrome in women with polycystic ovary syndrome. J Clin Endocrinol Metab 2005; 90: 1929-1935

6. Lankarani M, Valizadeh N, Heshmat R, Peimani M, Sohrabvand F. Evaluation of insulin resistance and metabolic syndrome in patients with polycystic ovary syndrome. Gynecol Endocrinol 2009; 25: 504-507.

7. Hosseinpanah F, Barzin M, Tehrani FR, Azizi F. The lack of association between polycystic ovary syndrome and metabolic syndrome: Iranian PCOS prevalence study. Clin Endocrinol 2011; 19: 692-697.

8. Revised 2003 Consensus on diagnosis criteria and long-term health risks related to poly cystic ovarian syndrome (PCOS). Hum Reprod 2004; 9: 41-47.

9. Soares EM, Azevedo GD, Gadelha RG, Lemos TM, Maranhao TM. Prevalence of the metabolic syndrome and its components in Brazilian women with polycystic ovary syndrome. Fertil Steril 2008; 89: 649-655.

10. Cheung LP, Ma RC, Lam PM, Lok IH, Haines CJ, So WY, et al. Cardiovascular risks and metabolic syndrome in Hong Kong Chinese women with polycystic ovary syndrome. Hum Reprod 2007; 23: 1431-1438.
11. Azizi F, Salehi P, Etemadi A, Zahedi-Asl S. Prevalence of metabolic syndrome in an urban population: Tehran Lipid and Glucose study. Diabetes Res Cklin Pract 2003; 61: 29-37.

12. Ford ES, Giles WH, Dietz WH. Prevalence of metabolic syndrome among US adults: findings from the third the National Health and Nutrition Examination Survey. JAMA 2002; 287: 356-359.

13. Brunner D, Weisbort J, Meshulam N, Schwartz S, Gross J, Saltz-Rennert H, et al. Relation of serum total cholesterol and high-density lipoprotein cholesterol percentage to the incidence of definite coronary events: twenty years follow up of the Donolo -Tel Aviv Prospective Coronary Artery Disease Study. Am J Cardiol 1987; 59: 1271-1276.

14. Jacobs DR Jr, Mebane IL, Bangdiwala SI, Criqui $\mathrm{MH}$, Tyroler HA. High density lipoprotein cholesterol as a predictor of cardiovascular disease mortality in men and women: the follow-up study of the Lipid research Clinics Prevalence Study. Am J Epidemiol 1990; 131: 32-47.

15. Kannel WB. Metabolic risk factors for coronary heart disease in women: perspective from the Framingham study. Am Heart J 1987; 114: 413-419. 